\title{
Segmentasi Pelanggan Internet Service Provider (ISP) Berbasis Pillar K-Means
}

\author{
Abd Hadi \\ STMIK Asia Malang \\ e-mail: hadi@asia.ac.id
}

\begin{abstract}
ABSTRAK Perusahaan penyedia layanan Internet Service Provider (ISP) memiliki jumlah pelanggan yang sangat banyak dan beragam. Dengan semakin banyak dan beragamnya jumlah pelanggan peusahaan akan sulit untuk mengetahui tipe pelanggan yang dimiliki oleh perusahaan. Akibatnya perusahaan akan kesulitan menerapkan strategi pemasaran yang tepat kepada konsumen. Dalam paper ini digunakan metode pillar K-means untuk melakukan segmentasi pelanggan. Algoritma pilar K-means untuk melakukan segmentasi pelanggaran . Algoritma pillar merupakan metode optimasi untuk menentukan centroid awal dalam algoritma K-Means. Dengan mengoptimasi centroid awal maka akan menghasilkan cluster yang lebih baik .setelah memperoleh hasil cluster yang optimal selanjutnya tipe pelanggaran dianalisis dengan menggunakan metode RFM (Recency, Frequency, Monetary). Hasil penelitian ini menunjukan bahwa pillar K-means mampu mengoptimasi hasil cluster $: \mathrm{k}=4$ dengan $\mathrm{a}=0.5$ dan $\mathrm{b}=0.8$ serta nilai silheoette $8=0.47103$. Dari hasil segmentasi 150 pelangganan diperoleh tipe pelangganan yang terdiri Most Valuable Customers (33) Most Growable Customers (41), Migrators (23) dan Below Zero (53).
\end{abstract}

Kata Kunci: segmentasi pelanggan, pillar K-Means, RFM

ABSTRACT. Internet service provider (ISP) service companies have a very large and diverse number of customers. With more and more number of company customers, it will be difficult to know the type of customer's company. As a result the company will have difficulty implementing the right marketing strategy to consumers. In this paper the Kmeans pillar method is used to segment customers. Pillar K-means algorithm for segmenting violations. The Pillar algorithm is an optimization method for determining initial centroid in the K-Means algorithm. By optimizing the initial centroid it will produce a better cluster. After obtaining the optimal cluster results, the types of violations are analyzed using the RFM (Recency, Frequency, Monetary) method. The results of this study indicate that the K-means pillars are able to optimize cluster results: $\mathrm{k}=4$ with $\mathrm{a}=0.5$ and $\mathrm{b}=0.8$ and silheoette value $8=0.47103$. From the results of segmenting 150 subscribers, the type of subscription consists of Most Valuable Costmers (33) Most Growable Costomers (41), Migrators (23) and Below Zero (53).

Keywords: customer segmentation, pillar K-Means, RFM

\section{PENDAHULUAN}

Saat ini data mining umumnya digunakan oleh perusahaan dengan jumlah pelanggan yang besar seperti perusahaan finansial, telekomunikasi, dan oranisasi marketing (Neethu 2012). Banyaknya jumlah pelanggan menuntut perusahaan memperhatikan customer relationship management (CRM). CM membantu membangun hubungan jangka panjang dengan pelanggan (Ling $\mathrm{R}$ dan Yen 2001). Factor kunci dalam pengembangan strategi CRM adalah memahami dan menganalisis perilaku pelanggan (Ngai dan Li Xiu 2009). PT Telkom sebagai salah satu perusahaan penyedia layanan telekomunikasi di Indonesia tentunya memiliki data pelanggan yang sangat besar, sehingga pengelolaannya memerlukan data mining. Data mining (DM) dapat digunakan oleh perusahaan untuk penentuan keputusan, peramalan, dan prediksi perilaku pelanggan di masa depan (Ngai dan Li Xiu 2009). Dengan menerapkan konsep analytical CRM dalam data mining, perusahaan dapat melakukan identifikasi pelanggan dengan melakukan segmentasi pelanggan.

Segmentasi pelanggan dilakukan untuk mengetahui perilakukan dan tipe pelanggan. Membentuk kedalam kelompok yang berbeda membatu meningkatkan kualitas rekomendasi, membantu perusahaan dalam membuat keputusan dengan mengidentifikasi pelanggan secara lebih jelas untuk mengembangkan strategi pemasaran yang lebih baik (Derya 2011). Tujuan utamanya adalah untuk mendatangkan keuntungan bagi pihak perusahaan.

Teknik yang dapat digunakan untuk segmentasi pelanggan adalah clustering merupakan pengelompokan sejumlah data atau objek ke dalam cluster yang sama (Kohe aria 2007). Metode yang paling umum digunakan dalam clustering adalah algoritma $K$-means. $K$-means merupakan metode clustering yang popular karena, K-means mempunyai kemampuan menggelompokan data dalam jumlah yang besar dan mampu mendeteksi outlier dengan cepat dan efisien (Kohe aria 2007). 
Permasalahan utama dalam metode $K$-means adalah penentuan pusat cluster yang dbandingakan secar acak. Karena penentuan titik awal dilakukan secara acak , $k$-means tidak menjamin hasil clustering yang unik (Shehroz 2004). Untuk dapat mengetahui perilaku dan tipe konsumen, perlu dilakukan optimasi pada algorima $K$-means sehingga menghasilkan cluster yang optimal.

Ada beberapa metode yang dapat digunakan untuk mengatasi permasalahan inisialisasi cluster dalam K-Means. Bradly dan Fayyad (1988) mengususlkan sebuah algoritma yang memurnikan initial points dengan menganalisis distribusi data dan probalitas kerapatan data (Bradley dan Fayyad 1988). Barakbah dan helen (2005) mebahas algoritma baru, yang disebut optimized K-means, ide utamanya adalah menyebarkan centroid awal dalam ruang fitur sehingga jarak di antara mereka menjadi sejauh mungkin (Barakbah dan Helen 2005). Barakbah dkk. (2005) menyajikan opimalisasi titik awal pada K-Means dengan menggunakan simulated annealing (Barakbah 2005). Barakbah (2006) mengusulkan algoritma baru untuk mengoptimalkan centroid awal pada penggunaan $K$-means dengan cara memisah penempatan centroid awal sejauh mungkin dalam pendistribusian data. Dengan mempertimbangkan perhitungan optimasi pada $K$-means. Barakbah dan Arai (2007) menyajikan algoritma untuk menentukan centroid awal dengan hierarchical K-means (Kohe aria 2007). Barakbah dan Kiyoki (2009) menyajikan pendekatan baru untuk optimasi K-means dengan perhitungan Distance Maximization untuk penentukan centroid awal yang disebut algoritma Pillar.

Berdasarkan penelitian terkait optimasi K-means yang telah dijabarkan maka dalam penelitian ini akan menggunakan PillarK-means untuk optimasi hasil dari segmentasi data pelanggan. Tujuan dari penelitian yang akan dilakukan adalah membentuk segmentasi data pelanggan dengan menggunakan Algoritma pillar K-means dan metode RFM untuk mengetahui tipe pelanggan dari PT. Telkom. Algoritma Pillar mampu mengoptimalkan pemilihan centroid awal dan meningkatkan ketepatan pada proses segmentasi di algoritma K-means. Algoritma pillar juga mampu menangani outlier dengan mekanisme outlier detection. Selain itu waktu eksekusi (execution time) algoritma pillar juga menunjukkan kinerja yang lebih baik daripada algorima optimasi centroid awal lainnya (Barakbah dan Kiyoki 2009).

Pembahasan terkaik paper ini akan dijabarkan sebagai berikut: Section 2 membahas tentang penelitian terkait. Section 3 membahas mengenai methodology yang meliputi deskripsi data. Kerangka penelitian, data preprosesing, analisis RFM, algoritma K-means, algoritma pllar dan evaluasi hasil cluster. Pada Section 4 akan dibahas mengenai hasil penelitian dan pembahasan. Kesimpulan akan dibahas pada Section 5.

\section{PENELITIAN TERKAIT}

Penelitian di bidang segmentasi pelanggan telah banyak dilakukan sebelumnya, ada berbagai metode yang digunakan dalam segmentasi pelanggan seperti misalnya dengan menggunakan SOM (self organizing map) (Rusmeier 1997), K-means (Qioru cha 2012), K-medoids (Han Zho 2014), Association Rule Mining (Gulluoglu 2015). Selain itu juga penelitian terkait segmentasi pelanggan mengkombinasikan dua metode atau lebih seperti Density Based DBSCAN dan K-means untuk segmentasi data perbankan (Zakrzawka 2005). Mengkombinasikan PCA (Principal Component Analysis) dengan Back Propagation Neutral Network untuk menganalisis prilaku konsumen (Han Minghua 2008). Seluruh penelitan yang dilakukan mampu membentuk segmentasi pelanggan dengan berbagai jenis studi kasus. Untuk penelitian pada bidang segmentasi pelanggan dengan menggunakan Pillar K-means belum pernah dilakukan sebelumnya.

\section{METODE PENELITIAN}

\section{A. Deskripsi Data}

Data yang digunakan dalam penelitian ini adalah data transakional PT. Telkom Indonesian pada tahun 2004. Data transaksional tersebut terdiri dari data Divisi Enterprise Service (DES) dan Divisi Busines Service (DBS). Data yang digunakan terdiri dari beberapa atribut seperti : ID nasabah, nama wilayah, produk, sub produk, ID wilayah, nama wilayah dan revenue. Setiap record data berisi catatan periode waktu transksi pelanggan. Periode waktu yang digunakan adalah satu bulan, dan berlangsung selama periode bulan Januari - Juli tahun 2014.

B. Kerangka Penelitian

Penelitian dimulai dengan melakukan pengumpulan data dan informasi. Selanjutnya dilakukan tahapan preprosesing dilakukan analisis RFM. Pada waktu segmentasi dilakukan proses clustering hasil cluster. Terakhir tipe pelanggan ditentukan dari hasil segmentasi analisis RFM. Kerangka penelitian dapat digambarkan sesuai Gambar 1. Program yang digunakan untuk analisis data adalah Phyton 2.7.10, dengan editornya menggunakan Sublime Text 3. 


\section{Preprosessing Data}

Sebelum dapat analisis, perlu dilakukan preprosessing terhadap data mentah yang diperoleh dan dijabarkan pada deskripsi data. Preproessing data merupakan langkah yang diperlukan untuk membuat proses knowledge discovery menjadi lebih mudah dan tepat. Data yang digunakan adalah data pelanggan dan data historikal transaksi penjualan PT. Telkom untuk periode Januari - Juli 2014. Data mentah yang dperoleh dari data pelanggan dan data hstorikal penjulan tersebut akan melalui praproses data yang meliputi :data integration,data cleaning, data transformation dan data selection.

Data integration merupakan proses untuk mengintegrasikan data yang berasal dari database yang berbeda. Data cleaning dilakukan untuk menangani data yang memiliki missing value. Data transformation bertujuan untuk merubah data menjadi format yang lebih sesuai. Data selection merupakan proses proses untuk memilih atribut yang akan digunakan dalam analisis. Proses data selection dilakukan dengan menggunakan metode RFM. Setelah dilakukan preprosessing data maka variabel yang digunakan dapat dilihat pada Gambar 2.

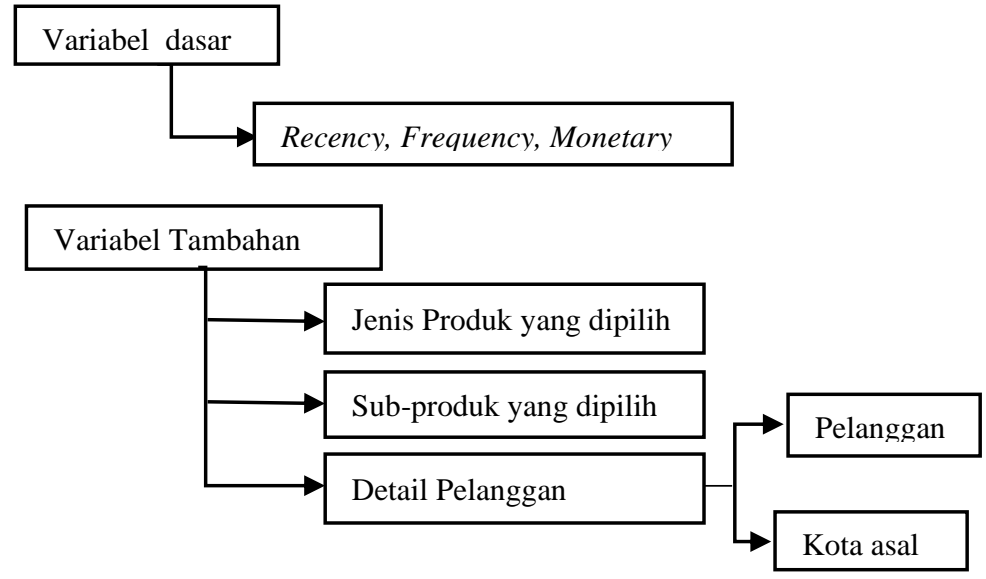

Gambar 1. Identifikasi Variabel hasil Preposessing

\section{Analisis RFM}

Konsep RFM diperkenalkan oleh Bult dan Wansbeek dan (1995) dan telah terbukti sangat efektif bila diterapkan pada database marketing (Blattbeng 2008). Analisis RFM tergantung pada Recency (R), Frequency (F),danMonetary (M). Ketiga komponen tersebut mempengaruhi kemungkinan transaksi terakhir yang dilakukan pelanggan. Recency, merupakan kriteria yang mengacu interval rntang waktu transaksi terakhir pelanggan dengan periode analisis. Frequency, mengacu pada jumlah transaksi dalam periode tertentu, misalnya hari, bulan atau tahun. Monetary, mengacu pada jumlah total transaksi dalam periode tertentu Analisis RFM digunakan untuk Scaling atribut $R-F-M$.

Langkah - langkah analisis RFM dapat dijabarkan sebagai berikut:

1. Urutkan data atribut R-F-M secara descending atau ascending.

2. Bagi ketiga atribut R-F-M kedalam 5 bagian, dan setiap bagian terdiri dar $20 \%$ nilai total. Kelima bagian akan diberi nilai 5, 4, 3, 2, 1, setiap angka tersebut. Mencerminkan kontribuksi tertinggi pelanggan. Nilai 5 mengacu pada pelanggan dengan kontribuksi tertinggi, nilai 1 mengacu pada pelanggan dengan kontribusi terendah pada revenue.

3. Ulangi lankah 1 dan 2 untuk setiap atribut R-F-M. Total 125 kombinasi $(5$ x 5 x 5) dengan atribut R-F-M berskala 5 (5, 4, 3, 2, dan 1). 


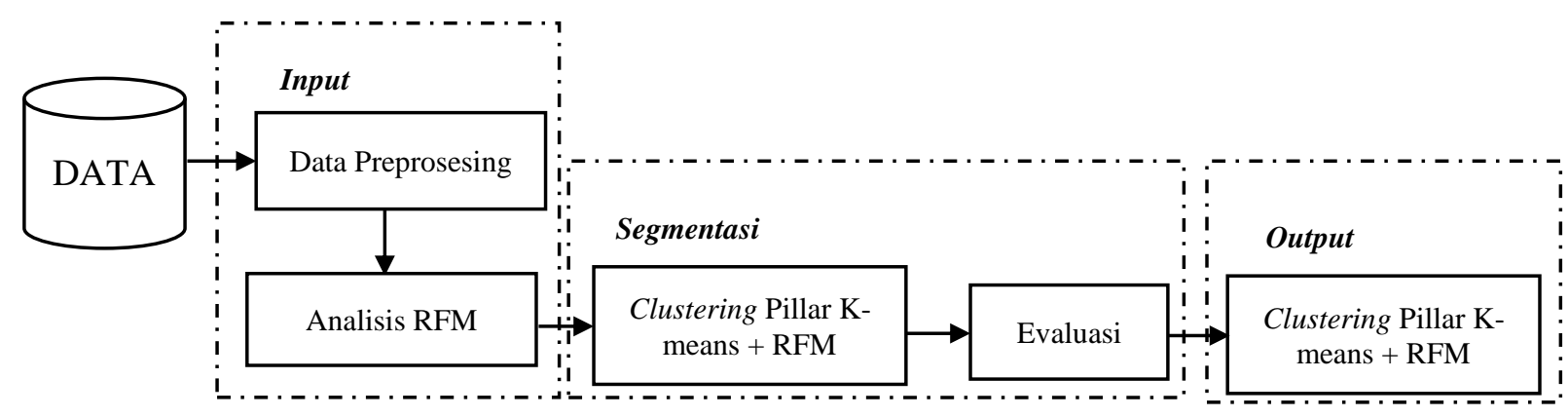

Gambar 2 Kerangka Penelitian Analisis RFM dan Segmentasi

\section{E. Algoritma K-means}

Algoritma $K$-means dapat dijabarkan dengan proses untuk menentukan pemetaan $f: D \rightarrow$ Cdari beberapa data $\mathrm{D}=\left\{d_{1}, d_{2}, \ldots, d_{n}\right\}$ dengan beberapa cluster $\mathrm{C}=\left\{c_{1}, c_{2}, \ldots, c_{n}\right\}$ berdasarkan similarity antara $d_{i}$. Misalkan $A=\left\{a_{i} \mid i=, \ldots, f\right\}$ menjadi atribut vektor $f_{-}$dimensi $\operatorname{dan} X=\left\{x_{i} \mid i=1, \ldots, k\right\}$ dimana $M_{\varepsilon} X$ adalah $M_{i}=\left\{m_{i j} \mid j=1, \ldots, n\left(s_{i}\right)\right\}$ sebagai anggota $s_{i}$, dimana $n\left\{s_{i}\right\}$ adalah jumlah anggota untuk $\left\{s_{i}\right\}$. Setiap cluster memiliki pusat cluster (centroid) dari tiap tiap element segmentasi. Algoritma clustering dapat dijabarkan sebagai berikut (Barakbah dan Kiyoki 2009).

1. Memulai algoritma dengan menentukan starting point centroid awal C secara acak.

2. Menghitung jarak $d$ antara $X$ kepusat cluster $C$. Untuk menghitung jarak dapat menggunakan Euclidean distance.

$$
\delta(x-y)=\|x-y\| 2=\left(\sum_{i=1}^{d}(x-y)^{2}\right) 1 / 2
$$

3. Pisahkan $x_{i}$ untuk $\tau=1, . . n$ ke $S$ yang memiliki nilai minimum $\partial\left(x_{i}, \mathrm{C}\right)$.

4. Tentukan pusat cluster baru $C_{i}$ untuk $i=1, \ldots k$.

$$
\mathrm{C}_{i}=\frac{1}{n_{i}} \sum_{j=1}^{n\left(s_{i}\right)} m_{i j} \epsilon S_{i}
$$

5. Kembali ke langkah 2, sampai semua centroid convergent.

Centroid dapat dikatakan Convergent jika posisinya tidak berubah lagi selama proses iterasi. Perubahan posisi centroid juga dapat berhenti pada iterasi ke $\tau$ dengan thresholde (Kovesi 2011).jika posisi tersebut telah diperbaharui oleh jarak yang lebih kecil $\varepsilon$.

$$
\left|\frac{C^{1}-C^{t-1}}{C^{1}}\right|<\varepsilon
$$

Optimasi penentuan centroid awal untuk algoritma $K$-means dapat dilakukan dengan menggunakan algoritma Pillar. Dalam penelitian ini algoritma Pillar digunakan sebagai penentu jumlah cluster optimal serta diguunakan untuk menentukan centroid awal untuk masing-masing cluster. Selanjutnya jumlah cluster optimal serta hasil perhitungan centroid awal pada algoritma Pillar digunakan pada algoritma $K$-means. Karena menggunakan centroid awal dari perhitungan algoritma Pillar maka penentuan centroid awal tidak lagi ditentukan secara acak.

\section{F. Algoritma pillar}

Algoritma pillar terinspirasi dari proses berpikir untuk menentukan satu set lokasi pillar untuk membuat bangunan atau rumah yang stabil. Dengan cara mendistribusikan posisi pillar sejauh mungkin antar satu sam lain pilar dapat menahan tekanan atap atau menstabilkan bangunan atau rumah. Distribusi pillar dianggap sebagai centroid sedangkan tekanan gravitasi dari atap dianggap sebagai distribusi data dalam sebuah ruangan vektor. Dalam algoritma Pillar penentuan posisi centroid awal berdasarkan akumulasi jarak terjauh centroid dalam distribusi data (Barakbah dan Kiyoki 2009). 
Algoritma Pillar dijabarkan sebagai berikut. Misalnya $X=\left\{x_{i} \mid i=1, \ldots, n\right\}$ merupakan data - data, $k$ adalah jumlah cluster, $\mathrm{C}=\left\{\mathrm{C}_{i} \mid i=1, \ldots, k\right\}$ merupakan inisialisasi centroid, $S X C X$ akan diindentifikasi untuk $X$ yang siap dipilih pada saat melakukan urutan proses. $D M=\left\{x_{i} \mid i=1, \ldots, n\right\}$ adalah akumulasi distance matrik,$D=\left\{x_{i} \mid i=1, \ldots, n\right\}$ adalah distance matrik untuk iterasi selajutnya (Barakbah dan Kiyoki 2009). Tahapan algoritma Pillar adalah sebagai berikut:

1. Set $\mathrm{C}=\varnothing, S X=\emptyset$ dan $D M=[$

2. Hitung $D \leftarrow$ dis $(X, m)$

3. Tentukan jumlah ketetanggan $N_{\min }=\propto \cdot n / k$

4. Tentukan nilai $d_{\max } \leftarrow a r_{\max }(D)$

5. Tentutkan batas ketetanggaan $n b_{\text {dis }}=\beta \cdot d_{\max }$

6. Tetapkan $i=1$ sebagai counter untuk menentukan centroid awal ke $-i$

7. $D M=D M+D$

8. Pilih $x \leftarrow x_{\operatorname{argmax}(D M)}$ sebagai kandidat untuk inisialisasi centroidke $-i$

9. $S X=S X U$

10. Tetapkan $D$ sebagai jarak antara matrik $X$ dan

11. Tetapkan $n o \leftarrow$ number data yang memenuhi $D \leq n b_{\text {dis }}$

12. Tentukan $D M(x)=0$

13. Jika $n o \leftarrow n_{\text {min }}$, kembali ke langkah 8

14. Tentukan $D(S X)=0$

15. $C=C \cup x$

16. $i=i+1$

17. Jika $i \leq k$, kembali ke langkah 7

18. selesai, $C$ adalah solusi cendroid awal yang optimal

\section{G. Pengujian Hasil Clustering}

Untuk mengetahui kualitas dari cluster yang dihasilkan dari proses clustering dengan menggunakan pillarK-means, maka cluster yang dihasilkan perlu diuji terlebih dahulu. Pengujian kualitas cluster dapat dilakukan dengan menggunakan fungsi silhouette (Peter J 1987). Fungsi silhouette menunjukkan apakah sebuah objek sudah tepat diletakkan pada suatu cluster atau tidak. Silhouette value $s=(i)$ dari objek $i$ dapat dijabarkan pada persamaan (4). Nilai dari $s=(i)$ berada pada rentang -1 dan $1 s \epsilon[-1,00,1,00]$.

$$
s(i)=\frac{b(i)-a(i)}{\max \{a(i), b(i)\}}
$$

Selain dengan menggunakan fungsi Silhouette, pengujian juga dapat dilakukan dengan menggunakan SSE (Sum squared Error) seperti yang dilakukan pada persamaan (5). Dimana $k$ adalah jumlah cluster dan $C_{i}$ merupakan pusat cluster $k e-i$.

$$
S S E=\sum_{i=1}^{K} \sum_{x \in c_{i}} \operatorname{dist}\left(c_{i}, x\right)^{2}
$$

\section{HASIL DAN PEMBAHASAN}

A. Hasil preprosesing dan analisis RFM

Dalam penelitian ini digunakan 150 record data pelanggan. Sebelum dilakukan analisis RFM dilakukan proses preprosesing yang terdiri dari data integration, data cleaning, data information dan data selection. Untuk mempermudah analisis diakukan scaling unuk masing masing atribut RFM. Hasil praproses data pelanggan disajikan pada Tabel 1. Proses scaling dengan skala 5 dilakukan dengan rentang $20 \%$ dari masing masing data, seperti pada tabel 2 . Hasil scaling data degan menggunakan analisis RFM disajikan pada tabel 3. 
Tabel 1. Data pelanggan

\begin{tabular}{|c|c|c|c|c|c|c|}
\hline ID & Kota & Produk & Sub produk & Recency & Frequency & Monetary \\
\hline B60 & $\begin{array}{c}\text { Jakarta } \\
\text { utara }\end{array}$ & $\begin{array}{c}\text { Pend content } \\
\text { speedy }\end{array}$ & $\begin{array}{c}\text { Legacy,wireline,isdn,dome } \\
\text { stic call,wline }\end{array}$ & Juli-2014 & 19 & 12.400 .000 \\
\hline B61 & Bogor & $\begin{array}{c}\text { Pend abonement } \\
\text { speedy multi speed }\end{array}$ & $\begin{array}{c}\text { New wave,wip,usage } \\
\text { wline,mouthly bee wline }\end{array}$ & Juni-2014 & 12 & 6.130 .000 \\
\hline B63 & $\begin{array}{c}\text { Jakarta } \\
\text { pusat }\end{array}$ & $\begin{array}{c}\text { Pend usage } \\
\text { communication, usage } \\
\text { wline,mouthly bee wline }\end{array}$ & April-2014 & 6 & 2.579 .00 \\
\hline
\end{tabular}

Tabel 2. Scaling data RFM

\begin{tabular}{|c|c|c|c|}
\hline Scaling & Reency (bulan) & Frequency & Monetary \\
\hline 5 & 7 & $>20$ & $>12.000 .000$ \\
\hline 4 & 6 & $16-20$ & $9.000 .001-12.000 .000$ \\
\hline 3 & $4-5$ & $11-15$ & $6.000 .001-9.000 .000$ \\
\hline 2 & $2-3$ & $6-10$ & $3.000 .001-6.000 .000$ \\
\hline 1 & $0-1$ & $0-5$ & $0-3.000 .000$ \\
\hline
\end{tabular}

Tabel 3. Hasil scaling data

\begin{tabular}{|c|c|c|c|c|}
\hline ID & Recency & Frequency & Monetary & RFM \\
\hline 060 & 5 & 4 & 5 & 545 \\
\hline 061 & 4 & 3 & 4 & 434 \\
\hline 062 & 3 & 2 & 1 & 321 \\
\hline 063 & 5 & 5 & 5 & 555 \\
\hline
\end{tabular}

Tabel 4. Jumlah cluster terbaik untuk setiap $k$, berdasarkan nilai silhouette.

\begin{tabular}{|c|c|c|c|c|}
\hline $\boldsymbol{K}$ & $\boldsymbol{\alpha}$ & $\boldsymbol{\beta}$ & Nilai silhouette & Jumlah cluster kosong \\
\hline 2 & 0.85 & 0.4 & 0.487646509 & 0 \\
\hline 3 & 0.3 & 0.4 & 0.569886169 & 0 \\
\hline 4 & 0.25 & 0.3 & 0.617346845 & 0 \\
\hline 5 & 0.3 & 0.3 & 0.561355816 & 0 \\
\hline 6 & 0.3 & 0.3 & 0.658983411 & 0 \\
\hline 7 & 0.4 & 0.3 & 0.80495978 & 0 \\
\hline 8 & 0.2 & 0.25 & 100000000 & \\
\hline 9 & 0.3 & 0.1 & 100000000 & \\
\hline 10 & & & 100000000 & \\
\hline
\end{tabular}


Tabel 5. Solusi cluster terbaik berdasarkan hasil analisis dan perhitungan SSE.

\begin{tabular}{|l|l|l|l|l|}
\hline A & $\beta$ & $\begin{array}{l}\text { Negative avg. } \\
\text { silhouette }\end{array}$ & $\begin{array}{l}\text { Cluster } \\
\text { kosong }\end{array}$ & SSE \\
\hline 0.45 & 0.75 & 0 & 0 & 3779.556 \\
\hline 0.5 & 0.8 & 0 & 0 & 3464.366 \\
\hline 0.55 & 0.75 & 15 & 0 & 3626.871 \\
\hline 0.65 & 0.8 & 15 & 0 & 3626.871 \\
\hline 0.7 & 0.75 & 16 & 0 & 3633.169 \\
\hline
\end{tabular}

Tabel 6. Penentuan tipe pelanggan

\begin{tabular}{|c|c|c|c|c|c|c|}
\hline Cluster & Ukuran & Avg.recency & Avg.frequency & Avg.monetary & Pola RFM & Tipe palanggan \\
\hline $\mathrm{C} 1$ & 33 & 4.727 & 4,758 & 4.636 & $\mathrm{R}$ 个 $\mathrm{F}$ M & $\begin{array}{l}\text { Most valuabe } \\
\text { customer }\end{array}$ \\
\hline $\mathrm{C} 2$ & 41 & 3.487 & 3.927 & 4.512 & $\mathrm{R} \simeq \mathrm{F} / \mathrm{M}$ 个 & $\begin{array}{l}\text { Most growable } \\
\text { customer }\end{array}$ \\
\hline $\mathrm{C} 3$ & 23 & 3.826 & 1.696 & 4.130 & $\mathrm{M} \uparrow$ & Migratos \\
\hline $\mathrm{C} 4$ & 53 & 3.712 & 4.000 & 2.308 & $\mathrm{R}-\mathrm{F}$ 个 $\mathrm{M}$ & Below zero \\
\hline total & 150 & 3.938 & 3.595 & 3.897 & & \\
\hline
\end{tabular}

B. Hasil segmentai dan pengujian hasil segmentasi

Dari hasil percobaan yang telah dilakukan ditemukan bahwa nilai $\alpha$ dan $\beta$ memiliki peran yang signifikan dalam menentukan nilai silhouette. Percobaan dilakukan dengan jumlah cluster $2 \leq K \leq$ 10. Diperoleh 178 hasil kombinasi nilai $\alpha$ dan $\beta$ untuk masing masing $K$ cluster berbeda. Karena banyaknya jumlah kombinasi maka hanya akan dianalisa hasil cluster dengan nilai silhouette tertinggi dari masing masing cluster. Nilai silhouette dapat terlihat pada tabel 4.

Pada tabel 4 terlihat bawa ada 3 nilai silhouette tertinggi pada jumlah cluster 8, 9 dan 10 . Namun apabila diamati, pada calster 9 dan 10 memiliki jumlah cluster kosong. Cluster kosong artinya ada cluster tanpa ada anggota cluster didalamnya. Berdasarkan hal tersebut maka ada 3 kondisi tambahan yatu digunakan untuk menentukan jumlah cluster optimal yaitu:

1. Jika tidak memiliki cluster kosong

2. Tidak memiliki nilai average silhouette yang negative. Hal ini karena niai silhouette terbear belum tentu menunjukan solusi cluster terbaik.

3. Dengan menentukan niai SSE (sum square error) terkecil.

Hasil pengujian menunjukan bahwa cluser terbaik adalah $K=4$ dengan $\alpha=0.5$ dan $\beta=0.8$ serta nilai silhouette $S=0.47103$, dan memenuhi ketga kriteria pengujian yang ada. Hasil pengujian selengkapnya disajikan pada tanggal 5 .

\section{Penentuan tipe pelanggan}

Hail segmentasi pelanggan dengan menggunakan pillar K-means menghaslkan empat cluster yang ditentukan berdasarkan transaksi terakhir (Recency), frekuensi pembelian (Frequency) dan total nilai pembelian (Monetary). Kombinasi input dari nilai RFM dapat ditentukan berdasarkan tanda $\downarrow$ atau $\uparrow$. Penentuan tanda tersebut berdasarkan rata rata nilai RFM, kemudian dibandingkan dengan total rata rata niai RFM. apabila nilai rata rata RFM lebih besar dari total rata rata nilai RFM 
maka diberi tanda $\uparrow$, sebaliknya jika lebih kecil akan diberi tanda $\downarrow$. tipe pelanggan yang dapat dibentuk adalah sebagai berikut:

1) Most valuable customer (MVC), merupakan kelompok pelanggan dengan customer value tinggi, pola RFM nya adalah $R \uparrow F \uparrow M \uparrow$

2) Most growable customer, merupakan kelompok pelanggan dengan potensi tinggi, pola RFMnya adalah $R \downarrow F \uparrow M \uparrow$

3) Migrator, merupakan kelompok pelanggan yang berbeda di antara below zeros dan most growable customer, pola RFM nya adalah $R \downarrow F \downarrow M \uparrow$

4) Below zeros, merupakan kelompok pelanggan dengan value yang rendah, pola RFMnya adalah $R \downarrow F \uparrow M \uparrow$.

Hasil penentuan tipe pelangan berdasarkan analisis RFM disajikan pada Tabel 6.

\section{KESIMPULAN DAN SARAN}

Hasil segmentasi pelanggan dengan menggunakan algoritma pillar K-Means menghasilkan jumlah cluster optimumK=4 Dengan $\alpha=0.5$ dan $\beta=0.8$ serta nilai silhouette $S=0.47103$. untuk menentukan kualitas hasil segmentasi tidak dapat hanya menggunakan satu parameter, melainkan depat menggunakan 3 parameter yaitu nilai silhouette,negative average silhouette dan sum square error (SEE). Dari hasil segmentai pelanggan diperoleh tipe pelnggan dengan rincian most valuable customers sebanyak 33 pelanggan, most growable customers sebanyak 41 pelanggan, migrators sebanyak 23 pelanggan dan below zero sebanyak 53 pelanggan.

\section{DAFTAR RUJUKAN}

Neethu Baby and Priyanka L.T customer classification and prediction based on data mining technique. International journal of emerging technology and advanced engineering, 2(12):314-318, December 2012.

$\mathrm{R}$ Ling and Yen D. Customer relationship management: An analysis framework and implementation strategies. Journal of computer information Systems, 41:82-97, 2001.

E.W.T. Ngai, Li Xiu, and D.C.K. Chau. Application of data mining techniques in customer relationship management: A Literature review and classification. Science direct expert Systems with applications, 36:2592-2602, 2009

Derya, Birant. Data Mining Using RFM Analysis, knowledge oriented applications in data mining, chapter 6 pages $91-108$. In Tech DOI: $10.5772 / 13683$. Available http.//www.intechopen.com/books/knowledge-oriented-applications-in-data-mining/data-miningusing-rfm-anaysis, 2011.

Kohei Arai and A. R. Barakbah. Hierarchical k-means; an algorithm for cendtroids initialization for $k$ means. Reports of the faculty of science and engineering, saga university, 36(1); 25-31, 2007.

Shehroz S. Khan and Amir Ahmad. Cluster center initialization algorithm for $k$-means clustering. Science Direct, 15;1293-1302, 2004.

P.S Bradley and U.M Fayyad. Refining initial points for k-means clustering. Proc. $15^{\text {th }}$ internat. Conf. on Machine Learning (ICMLS98), 1998

A.R Barakbah and Amir Ahmad. Cluster center initialization algorithm of initial centroids optimization for k-means. In proc. Soft Computing, intelligent system, and information technology (SIIT) 2005, number 2-63-66. Petra Christian University , 2005

A.R Barakbah, A. Fariza, and Y. Setiowati. Optimization of initial centroids for k-means using simulated annealing. In Proc. Industrial Electronics seminar (IES) 2005, pages 286-289. Electronic Engineering Polytechnic Institute of Surabaya-ITS, 2005.

A.R Barakbah. A new algorithm for optimization of k-means clustering with determining maximum distance between centroids. In proc. Industrial electronics seminar (IES) 2006, number 240-244. Electronic Engineering Polytechnic Institute of Surabaya-ITS, 2006

A.R Barakbah and Y. Kiyoki. A pillar algorithm for k-means optimization by distance maximization for initial centroid designation. In Symposium on, pages 61-68, March 2009.

H. Rushmeir, R. Lawrence, and G. Almasi. Case study: visualizing customer segmentation based on cluster analysis. In computer Science and Information Processing (ICMSE), 2012 International Conference on, pages 1189-1182, 2012 
Cai Qiuru, Lou Ye, Xi Haixu, Liu Yijun, And Zhu Guangping. Telecom costumer segmentation based on cluster analysis. In Computer Science and Information Processing (CSIP), 2012 International Conference on, pages 103-109, 2019

Zhao Han, Zhang Xiao -Hang, Wang Qi ,Zhang Ze-cong, and Wang Cen-Yue. Customer segmentation on mobile online behaviour. In management science \& engineering (ICMSE), 2014 international conference on, pages 103-109,2014.

S.S Sulluoglu. Segmenting customers with data mining techniques.in digital information, networking, and wireless communications (DINWC),2015 Thid Internatinal Conferences on, pages 154-159,2015

D.Zakrzewska and J. Murlewski. Clustering algorithms for bank customer segmentation. In intelligent systems design and applications, 2005.ISDA '05. Proceedings. $5^{\text {th }}$ INTERNATIONAL CONFERENCE ON PAGES 197-202,2005

Minghua Han. Customer segmentation model based on retail consumer behaviour analysis. In intelligent information technology application workshops, 2008. IITAW '08. International symposium on, pages 914-917, 2008.

R.C Blattberg, Kim B-D., and S.A. Neslin. Database Marketing: analyzing and managing customers. Springer, 2008.

B.Kovesi, J,M.Boucher,and S.Saoudi. Stochastic k-means algorithm for vector quantization. Pattern recognition lett, 22:603-610,2011.

Peter J. Rousseeuw. Silhouettes: graphical aid to the interpretation and validation of cluster analysis. Journal of computational and applied mathematics, 20:53-65, 1987.t 